\title{
Exploration on Sketch Teaching with Regional Culture as Its Core in Ordinary Universities
}

\author{
Hongyan $\mathrm{Yu}$ \\ Art Design Department \\ Humanities School \\ Yantai Nanshan University \\ Longkou County, Yantai, Shangdong, China, 265713 \\ e-mail:178859503@qq.com
}

\author{
Haifeng Dai \\ Art Design Department \\ Humanities School \\ Yantai Nanshan University \\ Longkou County, Yantai, Shangdong, China, 265713 \\ e-mail: 181992039@qq.com
}

\begin{abstract}
Sketching is one of teaching methods of fine arts and it plays a positive and irreplaceable role in contemporary fine arts education and has great significance. This paper analyzed the current status of fine arts sketch in colleges and universities, discussed how regional culture was reflected in the sketch teaching of colleges and universities under the multicultural background, and explored the teaching ideas of fine arts sketch with regional culture as its core, so as to promote a healthy, regular and beneficial development of sketch teaching.
\end{abstract}

Keywords—regional culture; colleges and universities; sketching; teaching exploration

\section{INTRODUCTION}

In Cihai, "sketching" is explained as "painting terminology, a way of directly sketching the object of observation. It can be used as a way of creation and it is commonly used in the practice of techniques and in collecting materials". [1] As a kind of sketching method and creation means, sketching is a required course for the contemporary major of fine arts in China's art colleges.

\section{SignificANCE OF SKETCHING COURSE}

Sketching is an important practice course, during which students observe, reproduce and create life and express emotions in natural life. It can improve students' ability to understand, grasp and display nature; it can improve students' ability to present color, shape model and explore techniques; it can enrich and develop sketching space and imagination for students to create works with great vitality and appeal.

As an educational course, apart from enabling students to recognize, feel, display and evaluate beauty, sketching can stimulate interest of students, broaden their horizons, develop their thinking, increase their knowledge and improve their humanistic quality under unconscious influence of sketching education to collect rich materials for future art creation.

The course of sketching in schools has features of scale group, unified action, orderly organization, regularity and so on. With development and implementation of sketching course in China's colleges and universities in recent years, corresponding teaching rules are gradually formed.
Some scenic spots seize the "market" of sketch and gradually establish a stable base for sketching to meet the demand of school painting. Currently, under the great influence of teachers or leaders of the department, sketching in colleges breaks the traditional sketching mode and gradually forms the habit of "going out for sketching".

Although immobilized sketching object has its advantageous aspects, it ignores deep study on culture during sketching process, ignores digging and use of colleges' surrounding regional culture, and ignores the important practical significance of college sketching performance for digging, spreading and displaying of regional culture. Therefore, we must combine going out for sketching with the college's surrounding regional sketch under the guidance of overall thought. It is one of the important ways to deepen the reform of sketch teaching in colleges and universities by carrying out sketch teaching activities with colleges' surrounding regional culture as its core.

\section{ANALYSIS ON CURRENT SitUATION OF SKETCH TEACHING ACTIVITY IN COLLEGES AND UNIVERSITIES}

Sketching is one of the fine arts education methods to directly face the depicted object of sketching and its teaching activity is an important practical teaching program for fine arts major in today's colleges and universities of China. Our country is vast with diverse topography and multi-national cultures coexist. Rich and colorful traditional ethnic culture forms and regional cultural features provide valuable materials for our sketch presentation and art creation. At present, as to the choice of college's practice base for painting, it often goes to the rather large ones, such as Hongcun sketching base in Anhui, Taihang Mountain sketching base in Henan, Wuyuan sketching base in Jiangxi, Mizhi sketching base in northern Shaanxi and so on. Fixed practice base for sketching is established in places concerned with well-known mountains and rivers, natural villages, ingenious and unique building groups and so on.

\section{A. The Reason Why Colleges and Universities Choose to Go Out for Sketching}

Colleges and universities have their reasons to choose those sketching bases. Firstly, it is the influence of fine arts teachers 
in colleges. Because of their sketching experience and sketching intention, going out sketching becomes a tendency. Secondly, most sketching bases have both beautiful natural landscape and human landscape with distinct features, displaying obvious local features, which are of great significance for fine arts teachers' and students' experience, learning and creation. Thirdly, this kind of sketching base provides relatively complete facilities and services, avoiding the life issue of taking into account basic necessities of life while leading a large number of students to teach them paint from nature for college teachers.

\section{B. Misunderstandings of Going Out for Sketching}

Due to long distance, fatigued and expensive journey to go out for sketching for most non-resident colleges and short period of sketching activity, sketching is limited in the shallow layer without excellent presentation and great connotation. Causes of this phenomenon are mainly: Misunderstanding One, the scenery outside is the most beautiful. In daily life, most people are accustomed to regarding surrounding scenery as ordinary and outside world as wonderful, and they neglect appreciation of scenery around them. Just as Luo Dan says, "We are in lack of eyes to find beauty instead of beauty in life." Misunderstanding Two, fashionable travel. The surface part of the college curriculum is sketching lesson, in fact, due to teachers' neglect of management and supervision, including unreasonable choice of sketching base and its arrangement, sketching is done hurriedly and superficially and it becomes tourism course, distorting the purpose of sketching course and interfering with normal teaching. "The only part of folk collecting and outdoor sketching during fine arts teaching of college is misled into romantic travel and adventure procurement by present commodity wave and tourism fashion." [2]p55 Misunderstanding Three, great gathering at sketching base. At present, several large sketching bases have been formed in China, such as Taihang Mountain, Mount Huangshan in Anhui, Northern Shaanxi, Yimeng Mountain in Shandong etc. As sketching season comes, all colleges and universities have flocked to sketching bases with teachers and students all over the mountain to paint, resulting in overcrowding.

\section{The Meaning of Regional CUlture to SKetch TEACHING}

"Culture refers to the unique cultural tradition which has a long history, lingers to today and still plays a role. It is the ecology, folk custom, tradition, habit and other forms of civilization of a specific area. Culture combines with environment in a certain area, so it holds the uniqueness of the region." [3]Regional culture bears irreplaceable core meaning in sketch teaching.

\section{A. Reduce the Cost of Going Out for Sketching}

Currently, the time for college's sketching course is generally 2 to 3 weeks. If the selected sketching base is far away from school, long journey will cost much time, sketching time will not be enough and it will be very difficult to enter the sketching state. In addition, because of unfamiliarity with environment, there is a big security risk. And high cost brings economic burden to some poor students, while local sketch can reduce some unnecessary expenses.

\section{B. Enough Time to Explore Local Culture Connotation}

Local sketch is not limited by time, so you can choose group sketching in class or paint during weekends and spare time. Since you take the most familiar surrounding natural scenery, social phenomena and human landscape as the object of sketching instead of seeking to run far or seeking new sights, there is enough time to explore and display regional culture connotation in your sketch continuously with in-depth layers.

\section{Necessary for Economy of College's Service Region}

Most local colleges are an important force in promoting and serving development of local economy and culture. Sketching based on local region enables students to further understand local culture and deeply explore regional features, gradually forming the image of local features, expanding the region's influence in the society and promoting development of local economy and culture.

\section{Promote Creation of Sketch Works Describing Regional Feature}

"The colorful outside world once makes people almost forget the homeland at their feet, neglect the ordinary real life world before their eyes and neglect the vivid stories which have happened or are happening around." [4]p3All artists take their most familiar, emotional and unique life as the subject of creation. With the beauty of homeland, Wu Guanzhong creates pieces of paintings of scenery in regions south of the Yangtze River; Luo Zhongli creates the great sketch of "Father" by truly portraying ordinary farmers around him... The practice proves that, regional culture has authenticity and uniqueness, which is the same as the purpose of art creation, and art creation based on regional culture is the pursuit of artists.

\section{The Establishment OF COLlege SKetch Teaching BASED ON REGIONAL CULTURE}

Currently, regional sketch teaching mode has been formed in a small number of colleges with outstanding unique regional culture. But sketching activity of most colleges is still a must be-out, blindly following the trend without forming the teaching idea of native painting, so there is still a long way to go to build a college sketch teaching system with regional culture as its core.

\section{A. Improve Understanding of Sketch Teaching in College with Regional Culture as its Core}

Sketching can not be simply seen as a means of art teaching, it is an important part of students' art creation as well as an important aspect of localization of running a college and promotion of local economic and cultural development. The sketch with regional culture as its core needs sufficient understanding and recognition from management departments of college, teachers in art schools and local government that sketch teaching and regional culture help each other forward. Action comes after unity of thinking. Only when agreement is 
reached by various departments, can teaching and development of local economy and culture be promoted.

\section{B. Deeply Explore Regional Cultural Features to Form Systematic Data}

"Regional culture is not only in old books, but in daily living reality, waiting for artists to discover and capture. Experience the deep connotation of ordinary life from a broken and grey thick wall, or visit the covered historical precipitation through the old thick dust on ancient wooden window, or interpret the ongoing contemporary evolutionary story from every trace of imprint of real life.'[5] P3 Regional culture does not stay in old books. Not only is local culture department eligible, but regional culture is the core of artists' review and investigation. Artists need to spend long time observing and studying to understand folk custom and to live with it, thus forming systematic regional culture data through in-depth experiencing, exploration and promotion. Take the above as the basis and carry out sketch teaching around regional cultural features. Promote reform and development of teaching with regional culture and regional culture develops and gets popularized at the same time.

For example, the unique geographical location of Shandong Peninsula forms the regional cultural feature of inland farming culture and coastal fishing culture. Coastal culture includes beer, navigation, fisheries, beach, $\mathrm{Xu} \mathrm{Fu}$ and so on; inland culture includes farming, Taoism, historical sites, sea power, building, folk custom and other culture essence. A set of Jiaodong cultural features are formed, including "Xian", "sea", "island", "ancient", "Taoism", "food" and "love".

\section{Establish Regional Culture Research Institute in Colleges}

Ordinary colleges in various parts of China are not only social talent training bases, but also scientific research bases, shouldering the great responsibility to inherit and develop national culture. And regional culture is one of the study objects. Set up regional culture research institute and research topic in colleges to carry out scientific research, team activities, visit and observation, folk collection, sketching and communication through exhibition. Besides, combine with Department of Tourism, the Propaganda Department and some other relevant local departments to hold various kinds of culture and art festival, art exhibition, photography exhibition etc. Thus, teaching achievement and scientific research achievement of teachers and students can be displayed, regional culture is popularized and its development is promoted, promoting economic and social prosperity.

Qingdao University adheres to carrying out scientific research around regional culture and its "Qingdao Local Culture Research Center" is one of the important research institutes approved to be established by government with authorization from Qingdao Municipal Propaganda Department, representing the important reform direction of Qingdao University's education development and scientific research based on regional culture.

The "National Cultural Industry Research Center" of Ocean University of China aims at research on development of national and regional cultural industry. Based on close combination of industry, education and research, it combines education and scientific research with culture, further promoting effectiveness of teaching and development of national and local economy. These are important reform practices to achieve sustainable development and the great revival of our country.

\section{Form Regional Sketching Groups}

Organize artists, sketching lovers or students from various districts and counties of the same region to look back at their homeland with the new look of a nonnative and experience the rich local cultural atmosphere instead of turning a blind eye to the familiar scenery, and try to examine, express and create in sketch language. Driven by the whole group and the target, sketch is used to interpret inner value of regional culture. Take regional culture as the theme for creation in academic activities and communications of the group to form like-minded art groups progressively. Then, go from art groups to art organizations and from organizations to art factions... Finally, self value and social value can be realized.

Here is a typical case. Every year, local professional painters and sketch teachers from various schools in Longkou City are organized to carry out regional sketch with in-depth local living and hold "Charming Longkou" sketch exhibition. During the process, painters exchange and communicate their feelings and experiences, and there are also collisions and debates of ideas and concepts; painters experience busyness and painstaking of sketching and creation and spark and joy of exploration and discovery. By displaying local cultural features of Longkou through painting, unique regional cultural deposits are discovered through sketching and creation of unique sketch works is promoted; it is adapted to the need of developing creative culture industry and it promotes development of regional culture invisibly.

\section{CONCLUSION}

Apart from exploration in education idea, system and other aspects in reform of China's higher education, curriculum reform should be considered. Reform is to break traditional shackles, consider the full range, enhance and improve your thought and achieve effectiveness in implementation action. Research on sketch teaching in colleges with regional culture as its core is to break traditional sketching modes, take local community as the basis, explore deeply, operate from a strategically advantageous position, and make teaching coexist with culture development, combine higher education with local culture and probe into unique education modes.

\section{REFERENCES}

[1] Wei Jiangong. Xinhua Dictionary. The Commercial Press, 1953.

[2] Zhang Haihua. Yu Jun. Integration of Folk Culture in Hakka Area and College Fine Arts Education and Practice Method. Hangzhou: Culture and Art Research, Oct. 2007.

[3] $\mathrm{Hu}$ Yaogang. Applaud for Regional Sketching Groups. The Art Newspaper, 2013-01-26 (3).

[4] Li Mengbin. Research on Tourism Resources Development Based on Regional Culture. Urban Construction Theory Research, 24th Issue, 2013 . 
[5] International Art. Applaud for Regional Sketching Groups. Bocai.com, 2015-1-3.

[6] Li Mengbin. Set Foot among Shade Trees and Look for the Charm of Clear Water - The Sixth Sketching Field Trip of Oil Painters from Jinhua, Lishui, Quzhou and Academy of Fine Arts of Zhejiang Normal University. Quzhou Daily, 2014-8-11. 